\title{
Konstruksi Nalar Teologi Politik Fundamentalisme Islam dalam Perspektif Epistemologi Bayani Muhammad Abid Al-Jabiri
}

\author{
Rohmatul Izad* \\ IAIN Ponorogo, Indonesia \\ Email: rohmatulizad@yahoo.com
}

\begin{abstract}
The political theology of Islamic fundamentalism is a religious-political movement that wants the total application of Islamic teachings in the political system and at the same time rejects all modern political ideologies. Meanwhile, bayani epistemology is one of the epistemological concepts found by al-Jabiri in expressing Arabic-Islamic reasoning based on holy texts, as well as being the basis for criticism of the tendency of textual epistemology in the tradition of Islamic historical literature. Therefore, research on the logical construction of Islamic fundamentalism political theology from the perspective of Muhammad Abid al-Jabiri's bayani epistemology is very relevant. The method used in this research is the literature review method of al-Jabiri's thinking with critical analysis. The results of this study: first, the method of thinking of Islamic fundamentalism political theology is based on text (nash) or literalism-takfirism. They make holy texts (al-Qur'an and Sunnah) as the only basis for knowledge to arrive at the truth. Their way of thinking revolves around the problem of the concept of text, namely the relationship between lafadz and meaning, Ușūl and furu ', as well as the position of the text between substance and accident. Second, the bayani dimension really colors the political theology of Islamic fundamentalism, which is textualistic and rejects all other epistemologies such as irfani and burhani. Based on textual reasoning, the theological reasoning of Islamic fundamentalism rests on three elements; (1) The dichotomous-dialectical paradigm, which sees everything in two opposing poles, such as black-and-white, right-wrong and good-bad. (2) Islamic reasoning, which is politically-theocentric, namely a thought that understands that Islam and the state are integral and Islamic law must be applied in the divine political order. (3) Political jihad as Jihād fī Sabilillāh, the jihad referred to here is war, both mental and physical. Jihad must be carried out to fight for an Islamic state as well as to fight against the enemies of Islam, both from within and from outside. This jihad is political in nature, but because it is based on religion, this jihad is considered as Jihād fī Sabīlillāh, which is a form of struggle in the path of Allah.
\end{abstract}

Keywords: epistemology of bayani; Islamic fundamentalism; textualism.

\begin{abstract}
Abstrak
Teologi politik fundamentalisme Islam merupakan gerakan politik keagamaan yang menginginkan penerapan ajaran Islam secara total dalam sistem politik dan sekaligus menolak seluruh ideologi politik modern. Sementara, epistemologi bayani adalah salah satu konsep epistemologi yang ditemukan oleh alJabiri dalam mengungkap nalar Arab-Islam berbasis pada teks suci, sekaligus menjadi basis kritik atas kecenderungan epistemologi tekstualisme dalam tradisi literatur kesejarahan Islam. Oleh sebab itu, penelitian tentang konstruksi nalar teologi politik fundamentalisme Islam ditinjau dari perspektif epistemologi bayani Muhammad Abid al-Jabiri menjadi sangat relevan. Metode yang digunakan dalam penelitin ini adalah metode kajian pustaka pemikiran al-Jabiri dengan analisis kritis. Hasil penelitian ini: pertama, metode berpikir teologi politik fundamentalisme Islam adalah berpijak pada teks (nash) atau literalisme-takfirisme. Mereka menjadikan teks suci (al-Qur'an dan Sunnah) sebagai satu-satunya landasan pengetahuan untuk sampai pada kebenaran. Cara kerja berpikir mereka berkisar pada masalah konsep teks, yakni hubungan antara lafadz dan makna, Ușūl dan furu', serta kedudukan teks antara substansi dan aksidensi. Kedua, dimensi bayani sangat mewarnai nalar teologi politik fundamentalisme Islam yang tekstualistik dan menolak seluruh epistemologi lain seperti irfani dan burhani. Dengan berpijak pada nalar tekstualis, nalar teologi politik fundamentalisme Islam bertumpu pada tiga unsur; (1) Paradigma dialektika-dikotomis, yang melihat segala sesuatunya dalam dua kutub yang saling berlawanan, seperti hitam-putih, benar-salah, dan baik-buruk. (2) Nalar keislaman yang politis-teosentris, yakni suatu pemikiran yang memahami bahwa Islam dan negara bersifat integral dan hukum Islam harus
\end{abstract}


Khazanah Theologia, Vol. 2 No. 3: 132-141

Konstruksi Nalar Teologi Politik Fundamentalisme Islam

dalam Perspektif Epistemologi Bayani Muhammad Abid Al-Jabiri

Rohmatul Izad

diterapkan dalam tatanan politik Ilahi. (3) Jihad politik sebagai Jihād fi Sabīlillāh, jihad yang dimaksud di sini adalah perang, baik perang pemikiran maupun fisik. Jihad harus dilakukan untuk memperjuangkan negara Islam sekaligus untuk melawan musuh-musuh Islam, baik dari dalam maupun dari luar. Jihad ini bersifat politis, tetapi karena berbasis agama maka jihad ini dianggap sebagai Jihād fī Sabīlillāh yang merupakan bentuk perjuangan di jalan Allah.

Keywords: epistemologi bayani; fundamentalisme Islam; tekstualisme.

\section{PENDAHULUAN}

Munculnya gerakan fundamentalisme Islam merupakan suatu gejala real dari apa yang disebut sebagai kebangkitan Islam (Islamic revivalism) dan Islam muncul kembali sebagai kekuatan politikglobal. Menurut Esposito (1996, hal. 34). Islam kembali muncul sebagai kekuatan global yang kuat dalam politik muslim pada tahun 1970-an dan 1980-an. Ruang lingkup kebangkitan Islam terjadi di seluruh dunia dari Sudan sampai Indonesia. Para pemimpin pemerintahan Islam dan oposisi juga menggunakan agama untuk melegitimasi dan menggerakkan dukungan rakyat.

Fundamentalisme Islam merupakan sebuah ideologi politik atas nama agama yang berupaya untuk memantabkan kembali agama Islam sebagai suatu sistem politik tunggal di masa modern. Dengan membuat term-term baru dan menafsirkan kembali konsep-konsep konvensional, fundamentalisme Islam menciptakan suatu paradigma baru yang terdiri dari unsur teoritis dan empiris (Burhanuddin, 2016, hal. 199).

Secara historis, istilah 'fundamentalisme' merujuk pada gerakan Protestan Amerika awal abad ke20 yang menyerukan untuk kembali pada penafsiran kitab Injil secara harfiah atau tekstual (Fuadi, 2013, hal. 115). Meski istilah ini tidak ditemukan padanannya dalam bahasa Arab, para peneliti agama, baik di Barat maupun di Timur, telah secara resmi menggunakan istilah fundamentalisme untuk menyebut suatu kecenderungan yang radikal dan konservatif dalam beragama. Sehingga penyebutan istilah 'fundamentalisme Islam' sendiri juga bersandar pada definisi ini, yakni suatu gerakan keagamaan yang memahami teks keagamaan secara harfiah dan nalar keislamannya cenderung tekstual, serta kurang memperhatikan landasan epistemologi yang lain dalam mencapai kebenaran.

Sementara itu, konsep 'teologi politik' yang termaktub dalam fundamentalisme Islam dapat dipahami sebagai suatu pendirian bahwa politik merupakan bagian integral dari ajaran Islam, sehingga apapun yang berkaitan dengan Islam, baik dari segi akidah maupun syariat, selalu dimaknai secara politis dengan menekankan pada nalar Islam yang teosentris. Pandangan semacam ini seringkali melahirkan gagasan Islam Din al-Daulah. Di antara gerakan teologi politik fudamentalisme Islam yang paling populer adalah gerakan Ikhwanul Muslimin di Mesir dan Jamaah Islamiah di Pakistan.

Menurut Armstrong (2002, hal. 236) salah satu ideolog fundamentalis awal adalah Maududi, pendiri Jamaah Islamiah di Pakistan, dia melihat kekuatan besar Barat bersatu padu untuk menghancurkan Islam. Kaum muslim, menurutnya, harus bersatu untuk melawan sekularisme yang merajalela. Selanjutnya tokoh fundamentalisme Islam yang berpengaruh setelah Maududi adalah Sayyid Qutb (1906-66), seorang anggota Ikhwanul Muslimin yang juga sangat dipengaruhi oleh Maududi.

Sebagai gerakan yang berorientasi pada teks, ada beberapa teori yang dapat menjelaskan tentang akar dan motif lahirnya fundamentalisme Islam. Pertama, akar historis fundamentalisme klasik, ini lahir dari suatu proses sejarah yang panjang yang dapat ditemukan pada gerakan pemurnian yang diusung oleh Ibn Taimiyyah. Kedua, akar fundamentalisme modern, motif kemunculan ini bisa dilihat dari respon kaum muslim terhadap kolonialisme, ideologi modernisme, juga sebuah respon terhadap Euforia pembaharuan. Ketiga, akar fundamentalisme post-modern, di era ini gerakan fundamentalisme Islam sudah berwujud organisasi-organisasi politik, seperti Ikhwan al-Muslimin di Mesir, Jamaah Islamiah di Pakistan, juga 
Khazanah Theologia, Vol. 2 No. 3: 132-141

Konstruksi Nalar Teologi Politik Fundamentalisme Islam

dalam Perspektif Epistemologi Bayani Muhammad Abid Al-Jabiri

Rohmatul Izad

organisasi politik internasional Hizbut Tahrir. Sementara itu, yang paling dekat dengan kecenderungan gerakan teologi politiknya adalah pada masa post-modern, mereka berjuang, di antaranya ingin mendirikan negara Islam atau sebuah kekhilafahan Islam secara internasional (Burhanuddin, 2016, hal. 201).

Fenomena gerakan teologi politik fundamentalisme Islam merupakan sebuah akar kebangkitan dari gerakan kaum muslim dan selalu menjadi perbincangan ilmiah sejak Revolusi Iran 1979. Menurut AnNa'im (2011, hal. 3), istilah fundamentalisme Islam digunakan untuk menyebut aktivis muslim kontemporer yang menuntut kesesuaian tuntas antara realitas dengan ajaran Islam, termasuk penerapan hukum publik syariah secara total dan segera.

Memang harus diakui bahwa kajian tentang fundamentalisme Islam sudah banyak dilakukan oleh para peneliti. Untuk menyebut beberapa saja, misalnya buku yang ditulis oleh Aksin Wijaya (2018) berjudul “Dari Membela Tuhan ke Membela Manusia; Kritik Atas Nalar Agamaisasi Kekerasan" yang terbit tahun 2018 oleh Penerbit Mizan. Judul buku ini secara eksplisit tidak menyebut kata fundamentalisme Islam, namun demikian penjelasan di dalamnya sangat penuh dengan term-term fundamentalisme Islam dan meletakkan fundamentalisme Islam sebagai objek kritik.

Ada pula buku yang ditulis oleh Hendropriyono (Hendropriyono, 2009) berjudul "Terorisme: Fundamentalisme Kristen, Yahudi, dan Islam". Buku ini mencoba mengkritik gerakan fundamentalisme dalam konteks tiga agama besar. Penulis buku ini menjadikan teori linguistik sebagai basis kritik terhadap fundamentalisme Islam. Penelitian ini cukup menarik karena mencoba melihat lebih jauh gerakan fundamentalisme dalam konteks terorisme. Maksudnya, akar-akar teorisme yang mengatasnamakan agama ternyata dapat ditemukan dalam gerakan fundamentalisme tersebut.

Dalam pengamatan peneliti, meski fundamentalisme Islam sudah banyak dikaji oleh para peneliti. Namun sejauh ini belum ada yang secara khusus mencoba menggali gerakan fundamentalisme Islam dalam konteks epistemologi, maksudnya mencoba menelusuri cara kerja suatu pemikiran dalam gerakan fundamentalisme Islam. Oleh karena itu, penelitian ini menjadi penting dilakukan di samping untuk memperluas cakrawala pemikiran Islam, juga memberikan perspektif baru tentang kritik nalar fundamentalisme Islam.

Penelitian ini akan menggali tentang gerakan teologi politik fundamentalisme Islam dalam perspektif epistemologi bayani Muhammad Abid al-Jabiri. Secara khusus peneliti akan mengkaji cara kerja suatu pemikiran dalam gerakan fundamentalisme Islam. Meski ini adalah gerakan ideologi politik keagamaan, dalam konteks ini peneliti penempatkannya dalam persoalan epistemologi Islam atau juga berarti salah satu kecenderungan pemikiran dalam Islam yang menempatkan teks sebagai aspirasi utama dan kekuatan ideologis dalam membangun sebuah argumentasi kebenaran terhadap gerakan teologi politik.

\section{HASIL DAN PEMBAHASAN}

\section{Riwayat Hidup Singkat Muhammad Abid al-Jabiri}

Nama lengkapnya adalah Muhammad Abid al-Jabiri, lahir di kota Fejij, Maroko Tenggara pada tahun 1935. Ia adalah anak satu-satunya dari pernikahan antara Muhammad dan Wazinah. Dari garis ibu, ia adalah keturunan dari Sayyid 'Abd al-Jabbar al-Fajiji, seorang ulama besar yang memiliki beberapa karya, yang manuskripnya masih tersimpan di perpustakaan pribadi salah seorang orientalis Perancis. Sedangkan dari keluarga ayahnya, mengalir darah nasionalis dan pejuang karena keluarganya, terutama 
Khazanah Theologia, Vol. 2 No. 3: 132-141

Konstruksi Nalar Teologi Politik Fundamentalisme Islam

dalam Perspektif Epistemologi Bayani Muhammad Abid Al-Jabiri

Rohmatul Izad

ayahnya adalah seorang nasionalis yang banyak memberikan kontibusi terhadap perjuangan gerakan kemerdekaan Maroko (Firdaus, 2014, hal. 17; Yesdaulet, Zhamashev, \& Rysbekova, 2020).

Al-Jabiri memperoleh pendidikan pertama di kampung halamannya, dengan pendidikan tradisional yang diadakan di masjid di bawah asuhan al-Hajj Muhammad Faraj sambil menyelesaikan pendidikan dasar formalnya di Sekolah Agama dan sempat merasakan pendidikan Sekolah Dasar Perancis dua tahun. Setelah itu, ia melanjutkan ke cabang Sekolah Swasta Nasional yang didirikan oleh al-Hajj Muhammad Faraj dan tokoh Gerakan Kemederkaan lain yang ada di Fejij. Ia menyelesaikan studinya di sekolah tersebut pada tahun 1949 (Firdaus, 2014, hal. 18).

Al-Jabiri lebih banyak menghabiskan pendidikannya dari tingkat dasar sampai perguruan tinggi di tanah kelahirannya di Maroko. Pernah satu tahun (tahun 1958) menempuh pendidikan filsafat di Universitas Damaskus, Syiria. Al-Jabiri menguasai tiga bahasa: Arab, Prancis, dan Inggris. Di tangan para filosof Perancis, khususnya Brunschvigg dan Bachelard, al-Jabiri memperoleh kematangan ilmu filsafat. Pengaruh kuat dari dua filosof ini tampak tidak dapat dipisahkan dari sosok al-Jabiri (Faisol, 2010, hal. 337).

Sebagaimana disebutkan di atas, tahun 1958 al-Jabiri belajar filsafat di Universitas Damaskus, Syiria. Akan tetapi ia tidak bertahan lama di Syiria, satu tahun kemudian ia pindah ke Universitas Rabat yang saat itu baru didirikan. Selama masa pendidikannya, ternyata ia terus menggeluti aktivitas politik, sampai kemudian tahun 1963 ia masuk penjara dengan tuduhan makar terhadap negara yang saat itu memang banyak disematkan kepada anggota partai UNFP (Aziz, 2016, hal. 163).

Pada masa muda, al-Jabiri memang dekat dan banyak dibimbing oleh Mehdi Ben Barka, salah seorang politikus ternama, pemimpin sayap kiri Partai Istiqläl yang mendirikan Union Nationle Des Forces Populaires (UNFP) dan di kemudian hari berubah namanya menjadi Union Socialiste de Forces Populaires (USFP). Kedekatannya dengan tokoh ini membawa al-Jabiri muda aktif dalam aktivitas politik. Mehdi yang menyarankan dan merekomendasikannya untuk menjadi humas Partai Istiqlāl (Firdaus, 2014, hal. 22).

Dalam proyek intelektual, tahun 1966 al-Jabiri bersama Ahmad as-Satatti dan Mustofa al-Gamari bekerjasama untuk menerbitkan text book tentang pemikiran Islam dan filsafat yang diperuntukkan bagi sarjana muda di tahun akhir sebelum mereka menyelesaikan pendidikan. Selama kurang lebih satu periode beberapa aktifitas al-Jabiri, baik dalam ranah intelektualitas maupun beberapa forum lain, telah membentuk al-Jabiri menjadi intelektual yang sangat penting di era itu. Beberapa artikel dengan beragam isu yang dihembuskan berhasil dipublikasikan di Maroko.

Al-Jabiri menyelesaikan program magister tahun 1967, dengan judul tesis Falsafah al-Tarikh 'Inda Ibn Khaldun, di bawah bimbingan M. Aziz Lahbabi. Saat itu dia sudah mulai mengajar filsafat di Universitas Rabat Maroko. Menurut catatan Aunul Abied Shah (2001, hal. 301), pada tahun 1970, al-Jabiri menyelesaikan studi program doktoral dan memperoleh gelar Ph.D dengan disertasi yang membahas tentang pemikiran Ibn Khaldun, yaitu "Fanatisme dan Negara: Elemen-Elemen Teoritik Khaldunian dalam Sejarah Islam" (al- 'Asabiyyah wa Dawlah: Ma'alim Nazariyyah Khalduiyyah fit Tarikhil Islami), disertasi ini di bawah bimbingan Najib Baladi.

\section{Fundamentalisme Islam}

Dalam tradisi Islam, terjemahan harfiah "fundamentalisme" ke dalam bahasa Arab adalah Ușūliyyah, kata yang merujuk pada penelitian atas sumber-sumber muslim sebagai aturan dan prinsip hukum Islam (Fauzan, 2010). Sebagaian besar para ilmuwan dan pengkaji Islam, khususnya di Barat tidak berurusan dengan ilmu Islam ini, atau tidak memahami gerakan fundamentalisme Islam dalam pengertian harfiah ini, melainkan memiliki perhatian-perhatian yang sangat berbeda. Oleh sebab itu, menurut 
Khazanah Theologia, Vol. 2 No. 3: 132-141

Konstruksi Nalar Teologi Politik Fundamentalisme Islam

dalam Perspektif Epistemologi Bayani Muhammad Abid Al-Jabiri

Rohmatul Izad

Armstrong (Armstrong, 2001, hal. 17), penggunaan istilah "fundamentalisme" dalam Islam agaknya sedikit menyesatkan. Namun, orang-orang lain sekedar mengatakan bahwa suka atau tidak, kata "fundamentalisme" ini tetap saja ada meskipun tidak sempurna. Tetapi merupakan cap atau label yang berguna dalam mengambarkan gerakan-gerakan yang, meskipun berbeda, memiliki kesamaan yang kuat.

Sebagian tokoh-tokoh intelektual menolak penggunaan klaim ini karena dianggap sebagai bias Barat seperti asumsi Riffat Hasan dan Fazlur Rahman, juga Friederick M, Denny, Bernard Lewis dan Sayyid Husein Hasr yang menyayangkan istilah tersebut, sebab akan memberikan menjelasan yang bisa menyesatkan akibat pemaknaan yang memang berangkat dari perbedaan framework baik dalam konteks sosial, kultural, ataupun latar belakang lahirnya (Hassan, 1993, hal. 33). Meskipun demikian, Garaudy yang kemudian diikuti oleh Azyumardi Azra menganggap hal itu sebagai suatu keniscayaan sebab fundamentalisme adalah terminologi umum yang bisa diaplikasikan dalam fenomena agama apapun (Azra, 1993, hal. 31).

Fundamentalisme Islam memiliki sejumlah karakteristik yang dapat dengan mudah dikenali. Dalam masalah politik, partai-partai yang bercorak fundamentalis lebih menekankan pada atribut atau simbol-simbol khusus, seperti "negara Islam" atau "Islam dijadikan sebagai sumber falsafah negara". Penekanan kepada sejumlah label tersebut didasarkan kepada keyakinan mereka bahwa syariat telah mengatur seluruh hal-hal yang berkenaan dengan kehidupan masyarakat, termasuk dalam wilayah politik. Lebih dari itu, fundamentalisme Islam menganggap bahwa aturan Islam tentang peri-kehidupan manusia yang lengkap dan menyeluruh tersebut juga berupa aturan-aturan yang detail terperinci. Oleh sebab itu, fundamentalisme Islam menolak konsep kenegaraan lain, terutama yang datang dari Barat (Mahendra, 1999, hal. 40).

Sejarah perkembangan istilah fundamentalisme bagi golongan Islam berhaluan keras mulai populer di dunia Barat sejak meletusnya Revolusi Iran pada tahun 1979 dalam melawan Amerika Serikat yang mereka sebut sebagai the Great Satan. Sejak saat itulah, istilah fundamentalisme kemudian digunakan untuk menggeneralisasi berbagai gerakan Islam di berbagai belahan dunia Islam sebagai gelombang kebangkitan Islam (Fuadi, 2013, hal. 117).

Dari kalangan penulis Barat, seperti oleh Hrair Dekmejien, sebagaimana dikutip oleh Fuadi (2013, hal. 117), bahwa pada tingkat tertentu fundamentalisme memiliki kesamaan dengan gerakan-gerakan serupa yang terjadi dalam sejarah Islam klasik. Sebagai "ideologi protes" dan "ideologi kaum opisisi", fundamentalisme muncul sebagai perlawanan terhadap kelas yang berkuasa pada masa awal masyarakat Islam dengan kehadiran Khawarij yang menentang Khalifah Ali bin Abi Thalib pada 15 abad yang lalu. Prinsip-prinsip radikal dan ekstrem pada Khawarij adalah semboyannya lā Hukma illā Allāh.

Azyumardi Azra (1996, hal. 111) membagi fundamentalis kepada dua periodesasi; fundamentalisme Islam pra-modern dan fundamentalisme Islam modern. Yang pertama muncul disebabkan oleh situasi dan kondisi tertentu di kalangan umat Islam, karena itu ia lebih genuine dan inward oriented, yang beorientasi ke dalam diri kaum muslimin sendiri. Sedangkan yang kedua muncul sebagai reaksi terhadap penetrasi sistem nilai sosial, budaya, politik dan ekonomi Barat.

Di era modern, kelahiran organisasi-organisasi Islam seperti Ikhawul Muslimin di Mesir dan Jamaah Islami di Pakistan, pada perkembangannya menjadi pola dasar gerakan-gerakan fundamentalisme di banyak bagian dunia Islam. Organisasi Islam ini umumnya menjadikan konsep jihad sebagai prinsip utama untuk membenturkan dan seringkali menumpahkan darah, tidak hanya dengan Barat yang oleh Sayyid Qurb (1985) dianggap jahiliyah modern, melainkan juga sesama kelompok Islam sebagai sekutu Barat. Demikian pandangan fundamentalis ekstrem-radikal. 
Khazanah Theologia, Vol. 2 No. 3: 132-141

Konstruksi Nalar Teologi Politik Fundamentalisme Islam

dalam Perspektif Epistemologi Bayani Muhammad Abid Al-Jabiri

Rohmatul Izad

Sekalipun fundamentalisme secara historis memiliki akar kuat dalam sejarah Islam, akan tetapi dalam perkembangannya lebih banyak ditentukan oleh bentuk-bentuk dialektika hubungan antara Islam dan Barat. Ia lebih merupakan reaksi terhadap tatanan sosial politik yang diterapkan Barat terhadap sejumlah negara-negara muslim yang dianggap tidak seimbang dan diskriminatif (Mustofa, 2017). Dengan demikian, fundamentalisme tidaklah sepenuhnya baru. Dalam taraf tertentu seperti dijelaskan sebelumnya, fundamentalisme Islam memiliki akar yang kuat dalam sejarah Islam. Demikian juga keliru jika dikatakan bahwa munculnya fundamentalisme Islam semata-mata pengaruh ideologi Barat.

\section{Basis Nalar Berpikir Teologi Politik Fundamentalisme Islam dalam Perspektif Epistemologi Bayani Muhammad Abid al-Jabiri}

Dalam konteks pemikiran Islam, kelompok fundamentalisme Islam sering merepresentasikan pihak yang mengklaim dirinya sebagai yang paling autentik, paling benar, paling suci, dan semacamnya. Mereka melakukan truth-claim terhadap apa yang mereka yakini sebagai kebenaran yang harus diikuti oleh oleh pihak lain. Sementara itu, kelomok lain di luarnya menjadi target upaya-upaya pemurnian atau dakwah mereka. Al-Maududi dan Sayyid Qutb misalnya, merupakan figur-figur fundamentalisme Islam kontemporer yang memandang dunia secara Menikean, hitam-putih dan absolut.

Beberapa kasus berikut menjadi bukti korban pemikiran keislaman yang mengideologi dan mensakralkan tersebut. Misalnya, Thaha Husein divonis murtad hanya karena mempertanyakan autentisitas syi'ir jahiliah dan fungsinya dalam menafsirkan al-Qur'an. Ali Abdul Raziq divonis murtad hanya karena berpendapat bahwa tidak ada format pemeritahan khusus yang bernama khilafah dalam Islam, dan Nasr Hamid Abu Zaid divonis murtad hanya karena mengkritik pemikiran Imam Syafi'i dan para fuqaha. Gerakan Islam Ahmadiyah divonis sesat karena meyakini Mirza Ghulam Ahmad sebagai nabi selain Nabi Muhammad Saw. Gerakan Islam Syi'ah divonis sesat karena dituduh menolak para sahabat Nabi dan mempunyai kitab al-Qur'an sendiri (Wijaya, 2018, hal. 4).

Dalam konteks kasus di Indonesia, warga NU yang menjadi simbol gerakan Islam Sunni yang biasa bertawasul kepada Nabi Muhammad Saw. dan para ulama saleh, divonis melakukan bid'ah, syirik, dan kafir. Begitu juga masyarakat Indonesia juga divonis sesat karena menerima Pancasila sebagai ideologi negara dan tidak mendirikan negara Islam atau khilafah Islamiyah. Kekerasan fisik kepada mereka pun biasanya dilakukan dengan beragam bentuk seperti penghancuran rumah ibadah, pemukulan, dan pembunuhan bahkan dengan bom bunuh diri (Setara Institute, 2009).

\section{Paradigma Dialektika-Dikotomis}

Paradigma dialektika-dikotomis merupakan suatu cara pandang terhadap dunia dan realitas yang melihat segala sesuatu melalui dua model kecenderungan yang saling berlawanan. Misalnya, melihat objek sesuatu secara benar-salah, hitam-putih, baik-buruk, dan lain sebagainya. Cara pandangan semacam ini bersifat tertutup dan cenderung mengabaikan kemungkinan ketiga. Maksudnya, paradigma ini bersifat eksklusif karena kurang meminati kemungkinan makna lain selain kedua dikotomi itu.

Cara pandang dialektika dikotomis ini sangat mewarnai pola pemikiran orang-orang fundamentalisme. Misalnya Sayyid Qutb, ia melihat bahwa masyarakat hanya terbelah menjadi dua, yakni masyarakat muslim dan jahiliah. Yang dimaksud jahiliah ini bukan hanya orang-orang di luar Islam, bahkan orang Islam yang dianggap tidak sepaham dengan Sayyid Qutb, atau mereka yang pro terhadap 
Khazanah Theologia, Vol. 2 No. 3: 132-141

Konstruksi Nalar Teologi Politik Fundamentalisme Islam

dalam Perspektif Epistemologi Bayani Muhammad Abid Al-Jabiri

Rohmatul Izad

Barat, adalah jahiliah. Dengan begitu, masyarakat muslim, harus berjuang melawan orang-orang jahiliah tersebut meski mereka juga menganut agama Islam.

Salah satu alasan mengapa paradigma dialektika-dikotomis itu begitu mengakar kuat pada pemikiran kaum fundamentalis adalah berawal dari cara pembacaan terhadap teks. Kebanyakan dari mereka memahami teks secara literal atau harfiah semata, sehingga kurang mengeksplorasi maka kontekstualnya. Karena basisnya hanya teks, maka sesuatu yang dianggap di luar teks menjadi diragukan kebenarannya. Hal ini bisa dilihat ketika mereka mengutip Surat al-Maidah (44). Ayat ini berbicara tentang perintah Tuhan untuk menegakkan hukum atas perintahnya, bila tidak maka seseorang tersebut dapat disebut kafir, fasik, dan zalim. Padahal, ayat ini memiliki banyak tafsir dan tidak selalu bisa didimaknai secara tekstual (Hendropriyono, 2009, hal. 166).

\section{Nalar Keislaman yang Politis-Teosentris}

Nalar politik-teosentris dimaksudkan untuk menjelaskan suatu kecenderungan pemikiran dalam fundamentalisme Islam yang menginginkan hukum-hukum Tuhan diterapkan secara komprehensif di muka bumi, yang kemudian diwujudkan dalam bentuk negara Islam. Dalam bentuknya yang lebih teoritis, gerakan teologi politik fundamentalisme Islam adalah sebuah gerakan yang melakukan pencarian terhadap tatanan politik Ilahi. Jadi fundamentalisme dalam pengertian ini, bukanlah menyangkut masalah kekerasan tetapi tentang tatanan politik keagamaan.

Politik dalam Islam sering memunculkan dua kutub pandangan yang bersifat ekstrem. Kedua pandangan itu adalah; pertama, kelompok yang berpendirian bahwa politik merupakan bagian integral dari ajaran Islam. kedua, kelompok yang menolak politik bukan bagian dari ajaran Islam. Pandangan kelompok pertama melahirkan gagasan Islam Din al-Daulah, sementara kelompok yang kedua melahirkan negara sekuler. Walau demikian, ada juga pandangan lain yang berusaha mengkompromikan kedua pandangan tersebut. Terhadap kedua pandangan ini muncul pandangan yang moderat, yang mencari jalan tengah, yakni negara dapat saja mengadopsi nilai-nilai ajaran Islam dan tidak mesti mendirikan negara agama (Bawazir, 2015; Nur, 2016).

Sayyid Qutb sendiri menegaskan nalar politis-teosentris ini dengan sebutan tatanan Ilahi atau Hakimiyah illā Allāh (pemerintahan Allah) yang harus diterapkan ke seluruh Dar al-Islam. Tatanan Ilahi ini kemudian akan akan menciptakan revolusi Islam yang dirancang untuk mengarahkan ke perdamaian dunia di bawah syarat-syarat siyadat Islam (supremasi Islam) atas seluruh dunia. Inilah kewajiban agama untuk mengejar jihad sebagai "revolusi dunia Islam" dalam rangka mengatasi masyarakat jahiliah, yang identik dengan kafir (Tibi, 2012, hal. 58).

Jadi nalar politis-teosentris dari fundamentalisme Islam ini ingin mengubah hukum-hukum manusia (al-Häkimiyyah al-Basyariyyah) yang ada sekarang ini ke dalam hukum-hukum Tuhan (alHākimiyyah al-Ilāhiyyah). Al-Maududi sendiri menginginkan sebuah pemerintahan Tuhan berbasis teodemokrasi. Prinsip dasar pemerintahan yang dia tawarkan ini adalah bahwa yang mempunyai hak mutlak atas pemerintahan dan pensyariatan hukum hanyalah Allah, seperti tergambar dalam QS. Yususf 12: 40, Ali Imran 3: 154, al-Nahl 16:166, al-Maidah 5: 44, karena semua yang ada di alam ini adalah milik Allah. Tidak ada seorang pun yang mempunyai hak mutlak termasuk pada nabi, karena posisi nabi adalah mengikuti apa yang diwahyukan Allah kepadanya, dan manusia diperintahkan mengikuti nabi sebagai pelaksana legislasi hukum-hukum Tuhan (Wijaya, 2018, hal. 57).

Jihad Politik sebagai Jihād fī Sabīlillāh 
Khazanah Theologia, Vol. 2 No. 3: 132-141

Konstruksi Nalar Teologi Politik Fundamentalisme Islam

dalam Perspektif Epistemologi Bayani Muhammad Abid Al-Jabiri

Rohmatul Izad

Di erak klasik, jihad tradisional adalah perang yang dilakoni oleh Kesultanan Islam dan secara simbolik oleh khalifah yang berkuasa dalam kapasitasnya sebagai imam dari semua umat Islam. Khalifah bertindak sebagai kepala negara, dan perang jihad yang ia pimpin tunduk pada aturan mengenai taktik dan sasaran yang sah. Sementara jihad dalam pengertian kelompok fundamentalis, adalah bentuk dari reinterpretasi dari jihad, yakni rekonstruksi politis atas Islam. Kelompok fundamentalis menjadikan jihad sebagai ideologi yang diagamaisasikan dan melegitimasi bentuk peperangan ireguler sembari difokuskan pada perang pemikiran (Tibi, 2012, hal. 185).

Istilah jihād fi sabìlillāh sendiri menjadi konsep yang begitu menakutkan bagi dunia Barat dan bagi sebagian umat Islam. Sebaliknya, ia menjadi istilah dan ajaran suci bagi sebagian kelompok umat Islam, termasuk bagi al-Maududi dan Sayyid Qutb. Menurut al-Maududi, jihād fi sabīlillāh adalah peperangan yang bertujuan agar panji syariat Allah berkibar di muka bumi, dan agamanya menjadi sumpremasi di dunia. Dalam perjuangan itu, seseorang tentu harus mematuhi ajaran syariat, dan tidak boleh melanggarnya. Nabi bersabda, "Siapa saja yang berperang dengan tujuan agar agama Allah mencapai supremasi, berarti dia itu berperang fi sabilillāh". Kalau ini mereka lakukan, kata al-Maududi, maka mereka akan mendapatkan kebahagiaan yang abadi di akhirat kelak, seperti tertuang dalam QS. Al-Qashash 28: 83 (Wijaya, 2018, hal. 62).

Tujuan pengaitan istilah jihad dengan $f i$ sabïlillāh adalah agar konsep jihad tidak dimaknai dan dilakukan sembarangan. Pengaitan itu mempunyai maksud tertentu. Jihad yang dimaksud dalam Islam adalah suatu upaya seseorang atau kelompok umat Islam dalam mengerahkan segala usaha dan kemampuannya demi meruntuhkan rezim penguasa yang zalim untuk kemudian mengantinya dengan sistem baru yang sesuai dengan ajaran Islam. Pada titik inilah kelompok fundamentalis meletakkan jihad dalam koridor politik sebagai jihād fi sabīlillāh.

Menurut Saeed (2014, hal. 95), di era sekarang ada tiga bentuk ijtihad yang paling dominan, yakni ijtihad tekstualis, ijtihad eklektis, dan ijtihad kontekstual. Jihad tekstual mendasarkan pada nash, ijma dan qiyas. Ijtihad eklektis adalah suatu penjastifikasian terhadap persoalan-persoalan tertentu yang mendukung pendapat mereka. Sementara jihad kontekstual, lebih mengacu pada kontekstualisasi atau relevansinya dengan kondisi kekinian, jadi dalam memahami al-Qur'an yang dikedepankan adalah konteksnya, agar ayat tersebut sesuai dengan perkembangan zaman.

Kembali ke soal jihad, Sayyid Qutb sendiri ketika membahas soal jihad, ia merujuk pada pandangan Ibn Qayyim, dalam kitabnya Zad al-Maad, terutama pasal yang membicarakan ajaran Nabi Muhammad dalam hubungannya dengan orang-orang kafir dan munafik. Qutb menilai, banyak pemikir yang memaknai jihad tidak mesti berperang secara fisik, sehingga peperangan secara fisik dinilai sebagai kesalahan dalam memahami ajaran Islam. Menolak pandangan itu, Qutb menyarankan untuk melihat faktor-faktor dan tujuan mulalui jihäd fi sabïlilläh. Sebab, ber-jihad $f i$ sabïlillāh itulah Allah mengutus Nabi Muhammad dan menjadikannya sebagai Nabi dan Rasul terakhir. Islam adalah agama yang memproklamasikan kebebasan manusia dari penghambaan kepada manusia, dan mengembalikann manusia agar hanya menghamba kepada Allah, karena hanya Allah yang Mahakuasa atas segala sesuatu (Wijaya, 2018, hal. 73).

\section{SIMPULAN}

Dasar-dasar pengetahuan yang terkandung dalam teologi politik fundamentalisme Islam adalah menempatkan otoritas teks (nās) sebagai basis epistemologi tunggal dalam memproduksi pengetahuan tentang Islam. Pengetahuan yang murni berbasis teks tersebut, diproyeksikan menjadi kekuatan yang mewujud dalam ideologi politik keagamaan. Agamasisasi politik ini dimaksudkan untuk mempromosikan 
Khazanah Theologia, Vol. 2 No. 3: 132-141

Konstruksi Nalar Teologi Politik Fundamentalisme Islam

dalam Perspektif Epistemologi Bayani Muhammad Abid Al-Jabiri

Rohmatul Izad

suatu tatanan politik yang dipercaya beremanasi dari kehendak Tuhan, dan bukan berdasarkan kedaulatan rakyat. Sementara itu, terkait dengan cara kerja pemikiran yang berbasis pada nalar tekstualisme, ada tiga prinsip dasar dalam pembacaan terhadap teks keagamaan, yakni konsep teks antara lafadz dan makna, konsep ușūl dan furu', serta substansi dan aksisendi. Terkait dengan prinsip yang pertama, konsep lafadz dan makna mengandung dua aspek, yakni teoritis dan praktis, aspek teoritis berkisar pada pembahasannya pada bahasa, sedangkan aspek praktis terkait dengan penafsiran terhadap perintah syariat. Prinsip yang kedua, usul adalah pangkal ujung rantai dari hubungan timbal balik dengan furu', ușūl sendiri merupakan sumber pokok dalam memproduksi pengetahuan Islam. Prinsip yang terakhir, fundamentalisme Islam menempatkan teks sebagai substansi dan akal sebagai aksiden yang menjadi pelayan bagi otoritas teks.

Kedua, dimensi bayani dalam teologi politik fundamentalisme Islam terletak pada pembacaannya terhadap turāts (tradisi). Jika turath dimaknai sebagai warisan Islam pada masa lalu, maka kelompok fundamentalis menempatkan al-Qur'an dan sunnah sebagai otoritas tunggal dalam warisan Islam. Sehingga metode bayani sangat mewarnai kelompok ini dalam membaca turath Islam dan meninggalkan seluruh metode berpikir yang dianggap bukan warisan Islam, seperti irfani (intuisi) dan burhani (akal). Sementara itu, setelah peneliti menganalisis teologi politik fundamentalisme Islam dengan menggunakan epistemologi bayani al-Jabiri yang berpijak pada kritik nalar Arab-Islam, maka ditemukan kata-kata kunci pemikiran mereka yang bertumpu pada tiga unsur, yakni paradigma dialektika-dikotomis (dua kubu yang saling berlawanan), nalar keislaman yang politis-teosentris, dan jihad politik sebagai jihad fi sabilillah. Paradigma dialektika-dikotomis selalu memandang segala sesuatu pada dua kutub yang saling berlawanan, yakni hitam-putih, benar-salah, dan baik-buruk. Sementara nalar keislaman yang politisteosentris adalah suatu kecenderungan pemikiran yang menginginkan hukum-hukum Tuhan diterapkan secara komprehensif di muka bumi, yang kemudian diwujudkan dalam bentuk negara Islam atau tatanan politik Ilahi. Sedangkan konsep jihad politik sebagai, merupakan sebuah perjuangan pada tataran politik dengan menggunakan agama dan memperlakukan jihad politik sebagai jihad fi sabilillah. Mereka hendak memasukkan kembali agama ke dalam wilayah politik global dan untuk sampai pada titik itu, mereka harus ber-jihad fi sabilillah.

\section{REFERENSI}

An-Na'im, A. A. (2011). Dekonstruksi Syariah; Wacana Kebebasan Sapil, Hak Asasi Manusia dan Hubungan Internasioanal dalam Islam (A. Suaedy \& A. ArRany, penerj.). Yogyakarta: LKiS.

Armstrong, K. (2001). The Bettle of God: A History of Fundamentalism. New Yor: The Ballantine Publishing Grup.

Armstrong, K. (2002). Islam; A Short History. London: Phoenix Press.

Aziz, M. T. (2016). Interrealisasi Pemikiran Muhammad Abid Al-Jabiri Dalam Pendidikan Islam. Procceding of Internasional Conference On Islamic Epistemology. Muhammadiyah University Press.

Azra, A. (1993). Fenomena Fundamentalisme Dalam Islam, Survey Historis dan Doktrinal. Jurnal Ulumul Qur'an, Vol. IV(3).

Azra, A. (1996). Pergolakan Politik Islam dari Fundamentalisme, Modernisme hingga PostModernisme. Jakarta: Gramedia.

Bawazir, T. (2015). Jalan tengah demokrasi: antara fundamentalisme dan sekularisme. Jakarta: Pustaka Al Kautsar. 
Khazanah Theologia, Vol. 2 No. 3: 132-141

Konstruksi Nalar Teologi Politik Fundamentalisme Islam dalam Perspektif Epistemologi Bayani Muhammad Abid Al-Jabiri

Rohmatul Izad

Burhanuddin, N. (2016). Akar dan Motif Fundamentalisme Islam: Reformulasi Tipologi Fundamentalisme dan Prospeknya di Indonesia. Wawasan: Jurnal Ilmiah Agama dan Sosial Budaya, 1(2), 199-210. https://doi.org/10.15575/jw.v1i2.831

Esposito, J. L. (1996). Ancaman Islam; Mitos atau Realita (A. Abdurrahman \& Missi, penerj.). Bandung: Mizan.

Faisol, M. (2010). Struktur Nalar Arab-Islam Menurut Abid Al-Jabiri. Tsaqafah, 6(2).

Fauzan, F. (2010). Fundamentalisme Dalam Islam. Al-Adyan: Jurnal Studi Lintas Agama, 5(1), 4760.

Firdaus, M. (2014). Metode Kritik Nalar Muhammad Abid al-Jabiri. Mataram: IAIN Mataram.

Fuadi, M. (2013). Fundamentalisme dan Inklusivisme dalam Paradigma Perubahan Keagamaan. SUBSTANTIA: Jurnal Ilmu-Ilmu Ushuluddin, 15(1), 114-126.

Hassan, R. (1993). Fundamentals: A Testimony of The Truth [Mempersoalkan Istilah Fundamentalisme Islam]. Ulumul Quran, 4(3), 32-41.

Hendropriyono, A. M. (2009). Terorisme; Fundamentalisme Kristen, Yahudi dan Islam. Jakarta: Kompas Gramedia.

Mahendra, Y. I. (1999). Modernisasi dan Fundamentalisme dalam Politik Islam. Jakarta: Paramadina.

Mustofa, I. (2017). Terorisme: Antara Aksi dan Reaksi (Gerakan Islam Radikal sebagai Respon terhadap Imperealisme Modern). Religia, 15(1), 65-87.

Nur, A. (2016). Konsep Wasathiyah Dalam Al-Quran;(Studi Komparatif Antara Tafsir Al-Tahrir Wa At-Tanwir Dan Aisar At-Tafasir). Jurnal An-Nur, 4(2).

Quthb, M. (1985). Jahiliyah Abad Dua Puluh: Mengapa Islam Dibenci? Bandung: Penerbit Mizan.

Saeed, A. (2014). Pemikiran Islam; Sebuah Pegantar (A. Rafiq, penerj.). Yogyakarta: Baitul Hikmah Press.

Setara Institute. (2009). Laporan Kondisi Kebebasan Beragama/Berkeyakinan di Indonesia 2008: Berpihak dan Bertindak Intoleran: Intoleransi Masyarakat dan Restriksi Negara dalam Kebebasan Beragama/Berkeyakinan di Indonesia. Jakarta.

Shah, M. A. A. (2001). Islam Garda Depan: Mosaik Pemikiran Islam Timur Tengah. Bandung: Mizan.

Tibi, B. (2012). Islamism and Islam. USA: Yale University.

Wijaya, A. (2018). Dari Membela Tuhan ke Membela Manusia; Kritik atas Nalar Agamaisasi Kekerasan. Bandung: Mizan.

Yesdaulet, Y., Zhamashev, A., \& Rysbekova, S. (2020). Muhammad Abid Jabiri and his work "Critique of the arabic reason." Вестник КазНУ. Серия религиоведение, 22(2), 19-26. 